\title{
Evaluation of cold chain logistics capability in Sichuan province under the supply-side structural reforms
}

\author{
Yan Qi ${ }^{1, a}$, Chong Wang ${ }^{1, b,{ }^{*}}$ \\ ${ }^{1}$ School of Management, Sichuan Agricultural University, Chengdu, 611130, PR China \\ a E-mail address: 1569243588@QQ.com \\ b E-mail address: wc000500@163.com \\ * Corresponding author
}

Keywords: Supply-side structural reforms, Cold chain logistics capability, Analytic hierarchy process, Fuzzy comprehensive evaluation

\begin{abstract}
In recent years, the supply-side structural reforms has brought opportunities and challenges to the development of cold chain logistics, which has aroused many scholars' interest. Basing on the supply-side structural reforms, the paper evaluates the cold chain logistics capability in Sichuan province. Firstly, the paper constructs evaluation index system of cold chain logistics from the following aspects: the operation capability, economic capability, service level, technical level and relationship management level. And then we determine the weight of evaluation index about cold chain logistics capability through the analytic hierarchy process (AHP) method. After that, we use fuzzy comprehensive evaluation to evaluate the cold chain logistics capability in Sichuan province. Finally, we give relevant policy recommendations and corporate decision-making reference to promote the development of cold chain logistics in Sichuan.
\end{abstract}

\section{Introduction}

Now, the cold chain logistics industry is developing rapidly.Starting from market size, the data shows that the average growth rate is over $20 \%$ in the past three years,and the market prospect of cold chain logistics is promising. (China Reporting Hall, 2017) ${ }^{[1]}$.It is expected that the market size of China's cold-chain logistics will exceed RMB 500 billion by 2020 . In terms of policies, the government introduces a number of related policies to promote the rapid development of cold chain logistics. For example, in 2017 Chinese government issued the "Notice on the Central Government's Financial Support for the Development of Cold Chain Logistics”, listing 10 regions as demonstration provinces and districts, which include Shandong, Henan, Chongqing, Ningbo, Xinjiang, Hebei, Guangdong, Sichuan, Qinghai and Ningxia. The Chinese government will provide these districts financial support to construct cold chain projects (Ministry of Finance of the People's Republic of China \& Ministry of Commerce, 2017) ${ }^{[2]}$.Sichuan among them is a very important province for the production and consumption of cold chain logistics commodities, and cold chain logistics plays an important role in the development of regional economy.

However, there are still obvious problems about cold chain circulation in Sichuan and also in China. According to the statistics from the Chinese Association of Refrigeration, the ratio of cold chain circulation about vegetables, meat and aquatic products in China is $22 \%, 34 \%$ and $41 \%$ respectively(Chinese Association of Refrigeration, 2015) ${ }^{[3]}$. Compared with the level of cold chain circulation in European and American countries which is over 95\%, there is a long way to go. Yang (2014) ${ }^{[4]}$ points out that the main problems of the cold chain logistics are the lagging development of third-party logistics, the incompleteness of service network and information systems, and the high loss of cold chain logistics. While Sun $(2015)^{[5]}$ believes that the main problem is that a complete and independent cold chain system has not yet been formed. Now a large number of goods are basically transported and sold without cold chain. Chen $(2015)^{[6]}$ finds that the main problem is that cold chain facilities can not meet the demand of consumers for high quality. Shao et al. $(2015)^{[7]}$ propose that the greatest problem is the lack of overall planning and coordination between the upstream and downstream, which creates partial imbalance and mismatch in the supply 
chain.

Meanwhile, the supply-side structural reforms bring opportunities and challenges to cold chain logistics in Sichuan and China. With regard to opportunities, the supply-side structural reforms will promote the cold chain logistics enterprises to innovate the development strategy, to improve service quality while reducing costs, and will also promote structural upgrading of the production and consumption. Speaking of challenges, supply-side structural reforms have higher requirements for cold chain logistics. How to solve the obvious structural contradiction of logistics supply, and how to promote the upgrading about service content and quality in the cold chain logistics, which have become the key issues for the supply-side reforms in the cold chain logistics industry.

Therefore, this paper discusses the cold chain logistics capacity in Sichuan under the supply-side structural reforms, which can not only make clear the basic situation of cold chain logistics in Sichuan, but also provide suggestions for government and cold chain logistics enterprises to make reasonable decisions. So it contributes to the sustained and steady economic growth of Sichuan, and provides references of improving cold chain logistics for other areas which are similar to Sichuan.

\section{Evaluation index system of cold chain logistics capability based on the supply-side structural reforms}

Cold chain logistics capability is a hot issue in recent years, and many scholars have studied it. Zhao et al. (2013) ${ }^{[8]}$ point that the cold chain logistics capability is reflected in the production,storage, transportation and sales. They establish foundation for the future research. After that, Feng et al.(2014) ${ }^{[9]}$ introduce dynamic and synergetic thought into the evaluation model of supply chain logistics capability. They discuss the relationship between major elements of logistics and supply chain logistics capability. Then $\mathrm{W}$ Wu et al. $(2015)^{[10]}$ build a performance evaluation indexes system about aquatic product cold chain logistics in China, which involves aquatic product, customer, supply chain and society four dimensions. Ji and Li (2017) ${ }^{[11]}$ set up the index system of dairy product logistics through the FAHP method. Lun and Li(2017) ${ }^{[12]}$ select four main indexes to measure the development level of cold chain logistics in Shanxi Province, including facilities and equipment, marketization, transportation capacity and economic benefits. According to the main logistics activities of cold chain logistics enterprises, Chen et al. (2018) ${ }^{[13]}$ take the operation ability, relationship management ability, dynamic integration ability, synergy ability and service ability as the first level index, and then set the second level indicators. Bresolin C.S. et al. (2018) ${ }^{[14]}$ present an overview of relevant aspects concerning the Brazilian cold chain, and show the situation of Brazilian cold chain, including its infrastructure, energy sources and expenditures, legislation and technology.

Combining with cold chain logistics and supply-side structural reforms, many scholars make some breakthrough. Wu and Xie (2016) ${ }^{[15]}$ construct four first-level indicators and 18 second-level indicators, evaluating the logistics capability of 21 cities in Guangdong. Yang et al. (2017) ${ }^{[16]}$ adopt the entropy weight method and grey relational analysis to analyze the influence factors of cold chain logistics ability in the supply-side structural reforms, then putting forward suggestions.

According to the situation of the cold chain logistics and supply-side structural reforms, as well as the existing researches and dissertation, the index system of cold chain logistics capability is constructed as shown in Table 1. 
Table1. Evaluation index system of cold chain logistics capability under supply-side structural reforms.

\begin{tabular}{|c|c|c|}
\hline \multirow{17}{*}{ 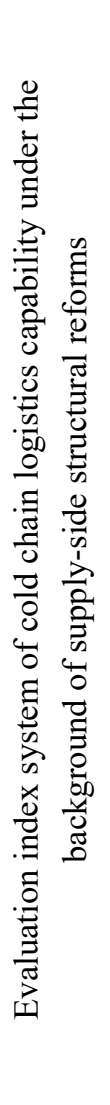 } & \multirow{5}{*}{$\begin{array}{l}\text { Operational capability of } \\
\text { cold chain logistics } \\
\text { (A1) }\end{array}$} & The reaction speed of market (B11) \\
\hline & & The flexibility of cold chain logistics (B12) \\
\hline & & The cost of logistics (B13) \\
\hline & & The logistics infrastructure (B14) \\
\hline & & The number of transfer stations (B15) \\
\hline & \multirow{3}{*}{$\begin{array}{l}\text { Economic capability of } \\
\text { cold chain logistics } \\
\text { (A2) }\end{array}$} & The total value of cold chain logistics (B21) \\
\hline & & $\begin{array}{l}\text { The ratio of cold chain logistics cost } \\
\text { to the logistics cost (B22) }\end{array}$ \\
\hline & & $\begin{array}{l}\text { The total rotting rate of } \\
\text { cold chain logistics goods (B23) }\end{array}$ \\
\hline & \multirow{3}{*}{$\begin{array}{l}\text { The service level of cold } \\
\text { chain logistics } \\
\text { (A3) }\end{array}$} & The rate of customer satisfaction (B31) \\
\hline & & The rate of customer complaint (B32) \\
\hline & & The response time to customer service (B33) \\
\hline & \multirow{3}{*}{$\begin{array}{c}\text { Technology level of cold } \\
\text { chain logistics } \\
\text { (A4) }\end{array}$} & The construction of information system (B41) \\
\hline & & $\begin{array}{c}\text { The application of } \\
\text { advanced logistics technology (B42) }\end{array}$ \\
\hline & & The renewal of cold chain logistics facilities (B43) \\
\hline & \multirow{3}{*}{$\begin{array}{c}\text { The relationship } \\
\text { management level in cold } \\
\text { chain logistics } \\
\text { (A5) }\end{array}$} & The trust degree (B51) \\
\hline & & The degree of standardization of cooperation (B52) \\
\hline & & Willingness to cooperate (B53) \\
\hline
\end{tabular}

In accordance with the evaluation index system of the cold chain logistics capacity, which was proposed by Chen (2018), this paper combines the focus of research — cold chain logistics capability under the supply-side structural reforms. This paper has made some revisions to its previous index system. The design of the system mainly emphasizes reducing costs, increasing efficiency and changing structural, which are the main characteristic of the supply-side structural reforms. After collecting many experts' opinions, the indicators for additions and changes are as follows.

(1) Economic capability of cold chain logistics. The index is of practical significance, which focuses on reducing costs and increasing economic results

(2) Technology level of cold chain logistics. Comparing with the previous index system, the paper stresses the importance of technical innovation in the supply-side structural reforms.

(3) Operational capability of cold chain logistics. The paper comprehensively considers the dynamic operation capability and static operation capability of cold chain logistics, such as the reaction speed of market, the flexibility of cold chain logistics, the cost of logistics, the logistics infrastructure and so on. That also embodies the consciousness of integration and upgrading of cold chain logistics capability.

\section{Weight of the evaluation index system of cold chain logistics capability under the supply-side structural reforms}

According to the expert evaluation method, this paper marks the evaluation index system of cold chain logistics capability. After sorting out the results, we get the data that we need in the process of calculation. The index system is graded by seven experts who are composed of managers in cold chain logistics enterprise, customers who are familiar with the cold chain logistics, and scholars who study the cold chain logistics. 
Table 2. The weight of cold chain logistics capability under supply-side structural reforms

\begin{tabular}{|c|c|c|c|c|}
\hline \multirow{19}{*}{ 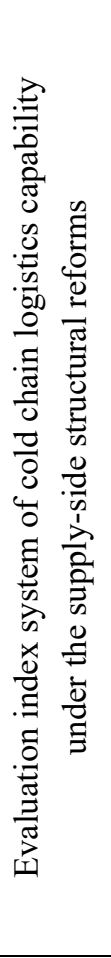 } & \multicolumn{2}{|c|}{ Layer A } & \multicolumn{2}{|c|}{ Layer B } \\
\hline & Index & Weight & Index & Weight \\
\hline & \multirow{5}{*}{ A1 } & \multirow{5}{*}{0.45} & B11 & 0.29 \\
\hline & & & B12 & 0.08 \\
\hline & & & B13 & 0.42 \\
\hline & & & B14 & 0.10 \\
\hline & & & B15 & 0.11 \\
\hline & \multirow{3}{*}{ A2 } & \multirow{3}{*}{0.23} & B21 & 0.10 \\
\hline & & & B22 & 0.36 \\
\hline & & & B23 & 0.54 \\
\hline & \multirow{3}{*}{$\mathrm{A} 3$} & \multirow{3}{*}{0.10} & B31 & 0.40 \\
\hline & & & B32 & 0.25 \\
\hline & & & B33 & 0.35 \\
\hline & \multirow{3}{*}{ A4 } & \multirow{3}{*}{0.14} & B41 & 0.32 \\
\hline & & & B42 & 0.41 \\
\hline & & & B43 & 0.27 \\
\hline & \multirow{3}{*}{ A5 } & \multirow{3}{*}{0.08} & B51 & 0.35 \\
\hline & & & B52 & 0.32 \\
\hline & & & B53 & 0.33 \\
\hline
\end{tabular}

Through the AHP, we get the weight of the evaluation index about cold chain logistics capability under the supply-side structural reforms. The result is shown in Table 2. From Table 2, we have the following results:

(1)Take operation capability of cold chain logistics as the core. When improving operational capability, we should pay attention to improving the reaction speed of market and reducing logistics costs.

(2)Focus on the economic capability of cold chain logistics. In the process of improving economic efficiency, we need lay stress on reducing the ratio of cold chain logistics costs to the logistics cost and the total rotting rate of cold chain logistics goods.

(3)Improving the cold chain logistics capability also requires improving logistics services and constantly applying new logistics technologies. The service is closely related to the consumers, and advanced technology is an important basis for other cold chain logistics capability. Therefore, they are an essential part of improving the cold chain logistics capability.

\section{Evaluation of the cold chain logistics capacity in Sichuan}

The paper takes the cold chain logistics capacity in Sichuan as an example. Combining with the index system and the weight of cold chain logistics capability under the supply-side structural reforms, we use multilevel fuzzy comprehensive evaluation to evaluate the cold chain logistics capacity in Sichuan. The specific process is as follows:

(1) Setting the related fuzzy sets

(1) Let $A$ denote the index set of primary factor layer: $A=\left\{A_{i}\right\} \quad i=1,2,3,4,5$.

(2) Let $B$ denote the index set of subfactor layer: $B_{i}=\left\{B_{i j}\right\} \quad i=1,2,3,4,5$.

$$
\mathrm{j}=1,2,3 \ldots \mathrm{k} \text {; }
$$

(3) Let $C$ denote the set of evaluation: $C=\left\{C_{h}\right\} \quad h=1,2, \ldots, n ; C$ is a collection of various evaluation results that the analysis object may make.

The values of the above are obtained by means of the AHP method that has been proved by the previous section of the paper (see Table 2).

(2) Setting up the fuzzy evaluation matrix 
Through the questionnaire and the expert evaluation method, we get the fuzzy evaluation matrix of $A_{1}$ index.

$$
R_{1}=\left(\begin{array}{cccc}
0 & 0.4 & 0.6 & 0 \\
0 & 0.2 & 0.8 & 0 \\
0 & 0.19 & 0.35 & 0.46 \\
0 & 0.2 & 0.7 & 0.1 \\
0 & 0.2 & 0.6 & 0.2
\end{array}\right)
$$

The weight of each factor in $A 1$ is $A_{1}=(0.29,0.08,0.42,0.10,0.11)$.

The result of fuzzy calculation is $A_{1}{ }^{\circ} R_{1}=(0,0.29,0.35,0.42)$.

The normalization of the result is

$$
A_{1}{ }^{\circ} R_{1}=(0,0.27,0.33,0.40) \text {. }
$$

In the same way, the other values can be calculated.

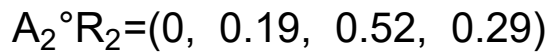

$$
\begin{aligned}
& \mathrm{A}_{3}{ }^{\circ} \mathrm{R}_{3}=(0,0.47,0.41,0.12)
\end{aligned}
$$

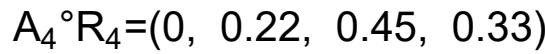

$$
\begin{aligned}
& A_{5}{ }^{\circ} R_{5}=(0,0.42,0.45,0.13)
\end{aligned}
$$

Consequently, according to the equations (1), (2), (3), (4), (5), we get the following results:

$$
R=\left(\begin{array}{l}
A_{1} \\
A_{2} \\
A_{3} \\
A_{4} \\
A_{5}
\end{array}\right)=\left(\begin{array}{llll}
0 & 0.27 & 0.33 & 0.40 \\
0 & 0.19 & 0.52 & 0.29 \\
0 & 0.47 & 0.41 & 0.12 \\
0 & 0.22 & 0.45 & 0.33 \\
0 & 0.42 & 0.45 & 0.13
\end{array}\right)
$$

The weight of the A layer corresponds to

$$
A=\left(\begin{array}{llll}
0.45, & 0.23, & 0.1, & 0.14,0.08
\end{array}\right)
$$

Thereby, $\quad A^{\circ} R=\left(\begin{array}{lllll}0.45 & 0.23 & 0.10 & 0.14 & 0.08\end{array}\right)^{\circ}\left(\begin{array}{llll}0 & 0.27 & 0.33 & 0.40 \\ 0 & 0.19 & 0.52 & 0.29 \\ 0 & 0.47 & 0.41 & 0.12 \\ 0 & 0.22 & 0.45 & 0.33 \\ 0 & 0.42 & 0.45 & 0.13\end{array}\right)$

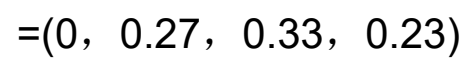

The normalization of result is $A^{\circ} R=(0,0.33,0.40,0.27)$

According to the principle of the best degree of membership, we know that the final value of the evaluation should be 0.40 , so under supply-side structural reforms the cold chain logistics capability is low in Sichuan province. The government and enterprises should formulate policies and decisions accordingly.

\section{Conclusion}

On the one hand, we get the conclusion that the cold chain logistics capacity needs to be further 
strengthened in Sichuan province. By the analysis of $A_{1}$ and $A_{2}$, we get that the operational capability and economic capability are weak in Sichuan province. So the related enterprises should focus the improvement of these two abilities. Further, it is necessary to focus on controlling logistics costs during improving operational capability, as well as controlling logistics costs during improving economic capability. By the analysis of $\mathrm{A}_{3}, \mathrm{~A}_{4}$ and $\mathrm{A}_{5}$, it is known that service level, technology level and relationship management level are better than operation capability and economic capability of cold chain logistics in Sichuan province.

On the other hand, establishing a comprehensive evaluation scheme is of great practical significance for improving regional cold chain logistics. Basing on the characteristics of the cold chain logistics and the supply-side structural reforms in Sichuan, this paper combines the AHP and the fuzzy comprehensive evaluation method to construct the evaluation index system of cold chain logistics capability. This paper applies the knowledge of fuzzy mathematics to the comprehensive evaluation of cold chain logistics capacity, which not only enriches the research in cold chain logistics, but also is suitable for improving cold chain logistics capacity in the provinces which are similar to Sichuan.

\section{Deficiencies and Prospects}

Although this study makes significant contributions to the literature and practices, it has several limitations. Firstly, we use the AHP and expert evaluation method to determine the importance of each index that may be influenced by subjective factors. Secondly, this paper needs a number of questionnaires to make the results more scientific and valuable, so as to provide strong support for government and enterprise to make decision.Thirdly, this paper only studies the evaluation index system of cold chain logistics capability under supply-side structural reforms in Sichuan. In the future, we can not only further explore the relationship among various indicators, but also discuss the relationship between the cold chain logistics capacity and the economic development or the national happiness index.

\section{Acknowledgement}

The authors are supported by the National Natural Science Foundation of China (No. 71602134) and Innovation Team of Education Department of Sichuan Province (No. 18TD0009).

\section{Reference}

[1] China Reporting Hall. China cold chain logistics market industry development prospect analysis and development strategy research report from 2017 to 2022,[EB/OL]. http://www.chinabgao.com.

[2] Ministry of Finance of the People's Republic of China \& Ministry of Commerce. Notice on the Central Government's Financial Support for the Development of Cold Chain Logistics,[EB/OL]. http://www.mof.gov.cn/index.htm.

[3] Chinese Association of Refrigeration. An analysis report on the development of China's refrigeration industry in $2015,[\mathrm{~EB} / \mathrm{OL}]$. http://www.car.org.cn.

[4] Jun Yang, Problems and countermeasures of cold chain logistics of agricultural products in Shenzhen, Central South University of Forestry and Technology, 2014. (in Chinese)

[5] AS. Sun, Analysis of the development of cold chain logistics in China, Traffic Construction and Management, v01.12, pp. 74-75,2013. (in Chinese)

[6] JY. Chen, and H. Huang. Study on Current Status and Countermeasures of Cold Chain for Fresh Agricultural Products Based on E-commerce,Science \& Technology Management Research, pp. 179-183, 2015. 
[7] WJ. Shao, K. Shou,Current situation of development and countermeasures and suggestions of Cold chain logistics of agricultural products in Jinhua City, Logistics Engineering and Management, vol.13, pp. 167-173, 2015. (in Chinese)

[8] DW. Zhao,Q. Liu, J. Liu, Study on the evaluation of the cold chain logistics service capacity of agricultural products, Management Modernization, vol.8,pp. 46-48, 2013.

[9] H. Feng, JL. He, Y.Liu. Data analysis of performance evaluation system of supply chain logistics capability,Journal of Zhongnan University of Economics and Law, vol.12, pp. 113-118, 2014.

[10] Wu, W., Deng, Y., Zhang, M., Wang, S., \& Zhang, Y. Study on Aquatic Products Cold Chain Logistics Performance Evaluation in China, pp. 1455-1463, 2015.

[11] WW. Ji, ZZ. Li, Analysis of factors influencing the transportation of dairy products cold chain logistics based on fuzzy analytic hierarchy process,Journal of Southeast University, vol.5, pp.54-56, 2016.

[12] MX.La, YP.Li, Comprehensive evaluation of cold chain logistics of agricultural products in Shanxi Province Based on FAHP, Agricultural Science in Shanxi, vol.45, pp. 1349-1352,2017.

[13] JM. Chen, F. Liu, ZW. He, Evaluation of cold chain logistics capability and regional differences of dairy products in Beijing Tianjin Hebei region, Chinese Animal Husbandry Magazine, vol.2, pp. 138-142, 2018.(in Chinese)

[14] Bresolin, C. S., Schneider, P. S., Rego, R., Filho, E. P. B. Brazilian cold chain panorama. International Journal of Refrigeration,vol.1, pp. 13-15,2018.

[15] CS. Wu, RH. Xie, Discussion on the logistics supply side reform of agricultural products in Guangdong Province-based on the evaluation of regional agricultural product logistics capability, Business Economy Research,vol.13, pp. 103-106, 2017.(in Chinese)

[16] FF. Yang, X. He, XF.Lin, Research on regional cold chain logistics capability under the supply side Reform--Taking Hainan Province as an example, Logistics Science and Technology, vol.40,pp.67-73,2017.

[17] YX, Wang. Problems and Countermeasures of Cold Chain Logistics for Chinese Agricultural Products, Logistics Engineering \& Management,vol.5, pp.32-36, 2011.

[18] XL.Fan, and BM. Zhang. Problem and Countermeasures of Fresh Agricultural Products in the Cold Chain Logistics System, Logistics Engineering \& Management, vol.12, pp. 25-29, 2016.

[19] F. Zhang, YI Jing, SO Business, GN University. Status of Development and Countermeasures Analysis about Agriculture Products Cold Chain Logistics in Jiangxi Province" Journal of Gannan Normal University, 2017. 